\title{
Flow instability prediction in low-pressure subcooled boiling flows using computational fluid dynamics codes
}

\author{
E. M. Dilla* $\quad$ G. H. Yeoh ${ }^{\dagger} \quad$ J. Y. Tu*
}

(received 25 October 2004, revised 21 November 2005)

\begin{abstract}
A proposed model for low pressure subcooled boiling flow was incorporated into the safety reactor code RELAP5/MOD3.2 to enhance the performance of the reactor code to predict the occurrence of the Ledinegg-type of instability in two phase flows. The nodalization scheme employed for the particular geometry as modeled in the RELAP5 code is described. The modified code was validated against experimental data and a marked improvement in predictive performance was noted. Simulation results using the modified RELAP5 code and CFX were also compared. Discrepancies between the modified
\end{abstract}

*School of Aerospace, Mechanical and Manufacturing Engineering, RMIT University, Victoria 3083, Australia. mailto: jiyuan.tu@rmit.edu.au

$\dagger$ Australian Nuclear Science and Technology Organization, PMB 1, Menai, NSW 2234, Australia.

See http://anziamj.austms.org.au/V46/CTAC2004/Dilla for this article, (C) Austral. Mathematical Soc. 2006. Published January 6, 2006. ISSN 1446-8735 
RELAP5 predictions and the experimental benchmark were observed, particularly on the influence of subcooling on the flow instability.

\section{Contents}

1 Introduction

C1337

2 Subcooled boiling model

C1339

3 Computational fluid dynamics codes

C1341

4 Simulation conditions

C1341

5 Results and discussion

C1344

6 Conclusion

C1349

References

C1350

\section{Introduction}

The study of the excursive-type flow instability (known as the Ledinegg-type instability) in low-pressure subcooled boiling flow is crucial for the safety analyses of research reactors. The occurrence of significant amount of bubbles in the channel flow can cause changes in the pressure drop, heat transfer performance, and oscillation or redistribution of flow rates in the case of parallel multi-channel systems $[13,9,17]$. This instability is important as far as the thermal margin is concerned because drastic changes in the flow may cause the critical heat flux ( $\mathrm{CHF}$ ) to be reached, which can lead to loss of coolant accidents $[10,11]$. The occurrence of the Ledinegg-type instability 
is greatly influenced by the operating conditions (for example, high inlet subcooling at low pressures) and system geometry [10].

Subcooled boiling flows have important implications in the nuclear industry $[13,9]$, more so for research reactors that operate under low pressures. Models for subcooled boiling flows that have been incorporated into reactor safety codes (such as CATHARE, RELAP5 and RELAP3D) still mainly cater for power reactors at high pressures. For subcooled boiling flows at low pressures, relevant models in these codes must be significantly modified and validated for applicability before they can become a powerful tool for undertaking any thermal-hydraulic safety analyses of research reactors $[9,17,16]$.

Recent numerical studies geared towards enhancing the predictive performance of the safety code RELAP5 under low pressure subcooled boiling conditions indicated promising results, although further improvements are still needed $[15,16]$. Among the key issues cited in recent research on low pressure subcooled boiling are the bubble dynamics parameters. These include bubble size distribution and interfacial area concentration [11], bubble departure diameter [6], and wall heat flux partitioning [9, 17]. The proper modeling of these factors is crucial to the precise prediction of the void fractions that characterizes low pressure subcooled boiling flows and better assesses the instabilities that may occur; suitable methods can then be devised for prevention or suppression of the phenomena.

The objective of the current work is to incorporate improvements into the safety code RELAP5/MOD3.2 and validate the modified code's suitability and predictive performance against experimental data. Likewise, comparison between the RELAP5/MOD3.2 and CFX predictions is highlighted. The simulation focuses on the phenomenon of Ledinegg-type instability in subcooled boiling flows. 


\section{$2 \quad$ Subcooled boiling model}

The two fluid mechanistic model of subcooled flow boiling [9, 17], where both the vapour and liquid phases are treated as continua, is employed. The model solves two sets of conservation equations governing mass, momentum and energy. Since the macroscopic fields of one phase are dependent on those of the other phase, closure relationships for the interaction terms coupling the transport of momentum, energy and mass of each phase across the interface are required. These terms such as inter-phase drag, heat and mass transfer terms in the field equations have been highlighted elsewhere $[17,15]$ and will not be repeated here.

The relevant modifications made to the subcooled boiling model in RELAP5/MOD3.2 are described as follows. For the evaluation of the Sauter mean bubble diameter, $D_{s}$, the correlation developed by Zeitoun and Shoukri [18] is adopted because of its applicability for subcooled boiling flow at low pressures:

$$
\frac{D_{s}}{\sqrt{\sigma / g \Delta \rho}}=\frac{0.0683\left(\rho_{l} / \rho_{g}\right)^{1.326}}{\operatorname{Re}^{0.324}\left(\mathrm{Ja}+\frac{149.2\left(\rho_{l} / \rho_{g}\right)^{1.326}}{\mathrm{Bo}^{0.487} \mathrm{Re}^{1.6}}\right)},
$$

where $\rho_{l}$ and $\rho_{g}$ are the liquid and saturated vapour densities, respectively, $\sigma$ is the surface tension, $g$ is the gravitational acceleration and the density difference $\Delta \rho=\rho_{l}-\rho_{g}$. The flow Reynolds number $\operatorname{Re}=G D_{h} / \mu_{l}$, where $G$ is the mass flux, $D_{h}$ is the hydraulic diameter and $\mu_{l}$ is the liquid viscosity. $\mathrm{Ja}$ is the Jacob number based on liquid subcooling and the boiling number Bo $=Q / G h_{\mathrm{fg}}$, where $Q$ is the wall heat flux and $h_{\mathrm{fg}}$ is the enthalpy difference between saturated vapour and liquid.

For the bubble departure diameter $d_{\mathrm{bw}}$ at the heated wall, the correlation of Kocamustafaogullari and Ishii [8] is employed:

$$
d_{\mathrm{bw}}=0.0208 \theta\left(\frac{\sigma}{g \Delta \rho}\right)^{1 / 2} .
$$


The equilibrium contact angle $\theta$ is taken to be 40 degrees as suggested by Rogers and Li [12].

The wall heat flux partition concept of Judd and Hwang [7] that is applicable for low-pressure subcooled boiling flow is adopted herein. The surface quenching heat flux

$$
Q_{q}=\left[\frac{2}{\sqrt{\pi}} \sqrt{k_{l} \rho_{l} C_{\mathrm{pl}}} \sqrt{f}\right] A_{q}\left(T_{w}-T_{l}\right) .
$$

Here, $k_{l}$ is the liquid thermal conductivity, $C_{\mathrm{pl}}$ is the liquid specific heat, $A_{q}$ is the fraction of the wall area subjected to cooling by quenching and calculated from $A_{q}=n\left(\pi d_{\mathrm{bw}}^{2} / 4\right)$ with $n$ as the active nucleation site density. $T_{w}$ and $T_{l}$ are the wall and liquid temperatures, respectively. The bubble departure frequency of Kocamustafaogullari and Ishii [8] is

$$
f=\frac{1.18}{d_{\mathrm{bw}}}\left[\frac{\sigma g \Delta \rho}{\rho_{l}^{2}}\right]^{0.25} .
$$

The density of active nucleation sites $n$ is obtained from Kocamustafaogullari and Ishii's correlation of data [8]:

$$
n=\frac{1}{d_{\mathrm{bw}}^{2}}\left[\frac{2 \sigma T_{\mathrm{sat}}}{\left(T_{w}-T_{\mathrm{sat}}\right) \rho_{g} h_{\mathrm{fg}}}\right]^{-4.4} f(\rho *) .
$$

The density ratio $\rho^{*}=\Delta \rho / \rho_{g}$, and the the known function of the density ratio $f\left(\rho^{*}\right)=2.157 \times 10^{-7}\left(\rho^{*}\right)^{-3.2}\left(1+0.0049 \rho^{*}\right)^{4.13}$.

The heat flux due to vapour generation at the wall in the nucleate boiling region can be calculated from Bowring [2] as

$$
Q_{e}=n f\left(\frac{\pi}{6} d_{\mathrm{bw}}^{3}\right) \rho_{g} h_{\mathrm{fg}},
$$

while the heat flux due to convection, according to the definition of local Stanton number St, is for turbulent convection

$$
Q_{c}=\operatorname{St} \rho_{l} C_{\mathrm{pl}} u_{l}\left(T_{w}-T_{l}\right)\left(1-A_{q}\right) .
$$




\section{Computational fluid dynamics codes}

RELAP5/MOD3.2 is a best-estimate thermal-hydraulic computer code for simulating hypothetical transients and accidents in water reactor coolant systems. The code simulates a two fluid system using a non-equilibrium nonhomogeneous six equation representation and applies to a wide range of reactor designs and transient/accident conditions [5]. RELAP5/MOD3.2 is used in nuclear safety analyses.

CFX4.2 is a general-purpose commercial CFD software with multi-phase capabilities suitable for predicting subcooled flow boiling. It is based on a conservative finite volume formulation using a structured, multi-block, nonorthogonal, curvilinear coordinate grid with a collocated variable arrangement [1]. The enhancements and user defined specifications to the CFX code used in earlier studies are detailed elsewhere [17] and are repeated here.

\section{Simulation conditions}

The experimental set-up consisting of a vertical, rectangular heated channel formed the basis for the simulation. The height, width and thickness of the channel flow are $600 \mathrm{~mm}, 38 \mathrm{~mm}$ and $3.6 \mathrm{~mm}$ respectively. Per RELAP5 nodalization requirements, the channel was converted into an annulus having an equivalent cross-sectional flow area and hydraulic diameter. This is because the code RELAP5 can only handle either a pipe or annulus test section. The annulus was judged to be the better configuration to provide appropriate cross sectional flow area representation for this case (for example, preserving the narrow gap characteristic of the experimental channel). The fluid used for this simulation is water.

The nodalization scheme for the annulus test section used in the simulation is shown in Figure 1. The heated test section (modelled by the annular 


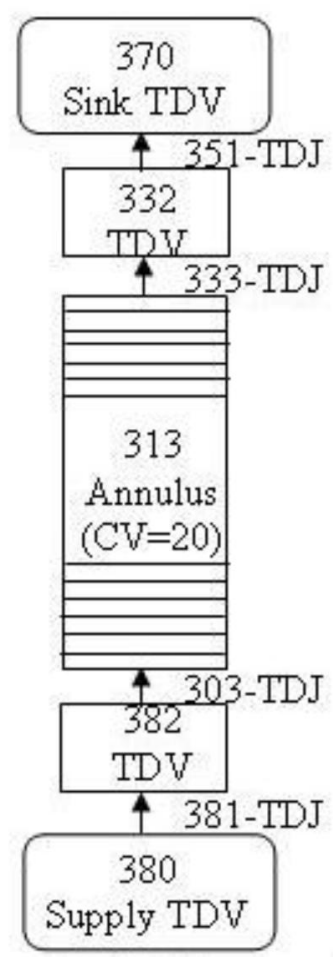

Figure 1: Nodalization scheme. 
TABLE 1: Experimental conditions

\begin{tabular}{|l|lll|}
\hline Cases & $\begin{array}{l}P_{\text {outlet }} \\
(\mathrm{kPa})\end{array}$ & $\begin{array}{l}T_{\text {inlet }} \\
\left({ }^{\circ} \mathrm{C}\right)\end{array}$ & $\begin{array}{l}Q \\
\left(\mathrm{MW} / \mathrm{m}^{2}\right)\end{array}$ \\
\hline $\mathrm{C} 1$ & 300 & 45 & 2.0 \\
$\mathrm{C} 2$ & 300 & 45 & 3.0 \\
$\mathrm{C} 3$ & 300 & 45 & 4.0 \\
$\mathrm{C} 4$ & 300 & 25 & 3.0 \\
$\mathrm{C} 5$ & 300 & 65 & 3.0 \\
\hline
\end{tabular}

component 313) was subdivided into 20 control volumes. The two flow development sections (time dependent volumes (TDV)) upstream and downstream of the test section where added to insure that the flow into the heated test section is fully developed. Time dependent junctions (TDJ) connect the volumes to complete the simulated system. Overall, the scheme consists of five time dependent volumes as well as four time dependent junctions.

Table 1 summarizes the scope of the experimental conditions tested during the simulation. The data were adopted from the CEA Grenoble experiments. The experimental variables $P_{\text {outlet}}, T_{\text {inlet }}$ and $Q$ refer to local parameters of the test section. More details regarding the experimental set-up, instrumentation and measurement uncertainties are reported in the two CEAGrenoble reports $[3,4]$. These experimental data were chosen because of the requirement to validate the model against the configuration of the eventual replacement of the present research reactor at ANSTO similar to those of the CEA test section geometry. 


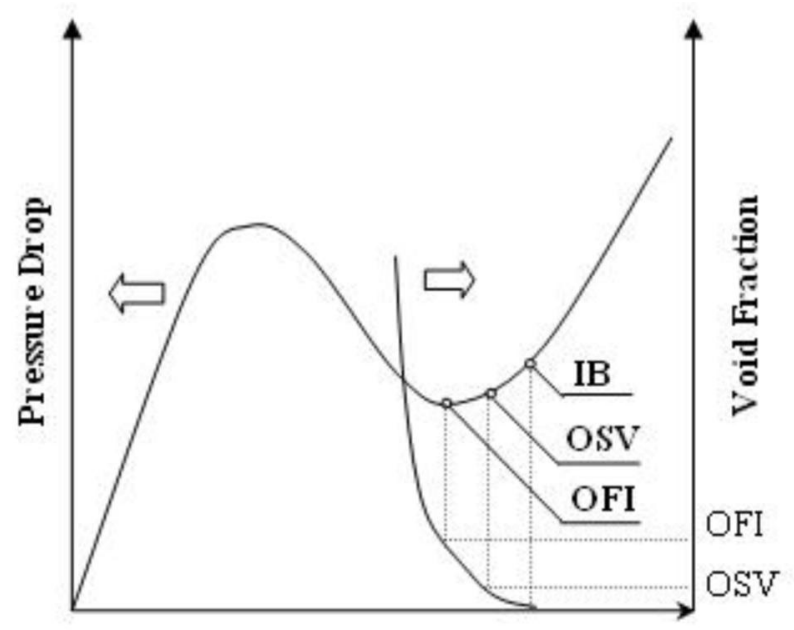

Flow Velocity

Figure 2: Flow Instability Schematic.

\section{$5 \quad$ Results and discussion}

The schematic representation to describe subcooled boiling flow instability is shown in Figure 2. At some point downstream of the coolant flow, when the wall temperature exceeds the saturation temperature of the liquid, nucleation is initiated at the point called incipient boiling (IB). Further downstream, the number of bubbles increases to what is known as the onset of significant void (OSV) point. At some point called the onset of flow instability (OFI), the bubbles generated in significant numbers, fill the channel and cause disruption in the flow. It is in the vicinity of this region where the Ledinegg-type of instability starts to manifest. The flow is unstable and is characterized by abrupt increases in pressure drop as well as flow oscillations.

Figures 3, 4 and 5 show the simulated pressure drop and the void fraction profiles in relation to inlet velocity of the heated section for surface heat 


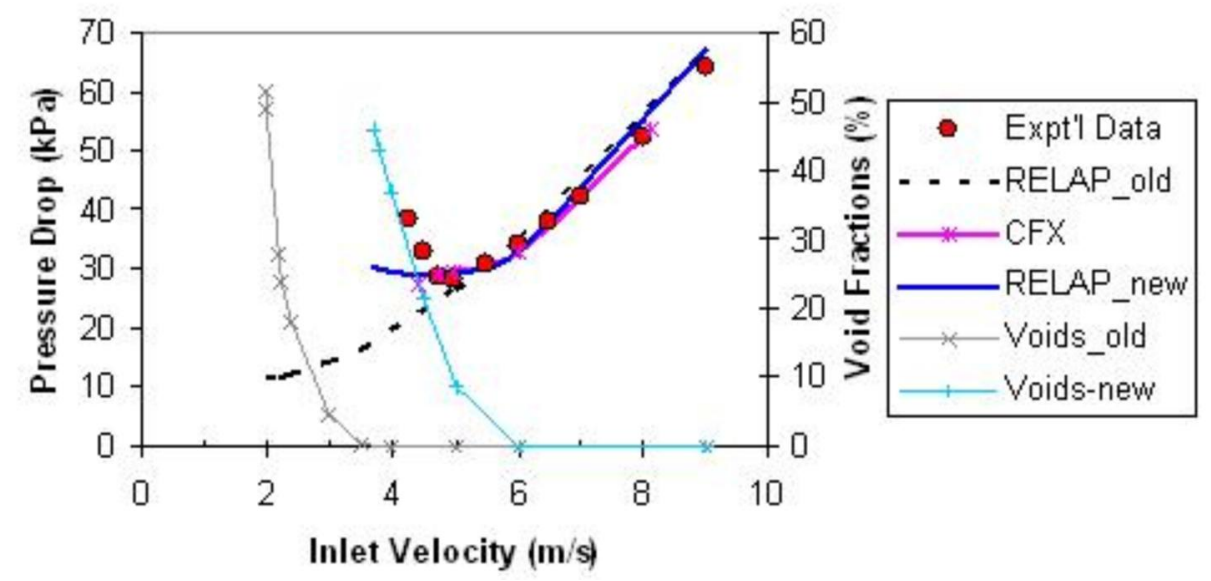

Figure 3: Pressure drop and void fraction profiles for an inlet temperature of $45^{\circ} \mathrm{C}$ and outlet pressure of $300 \mathrm{kPa}$ for a heat flux of $4 \mathrm{MW} / \mathrm{m}^{2}$.

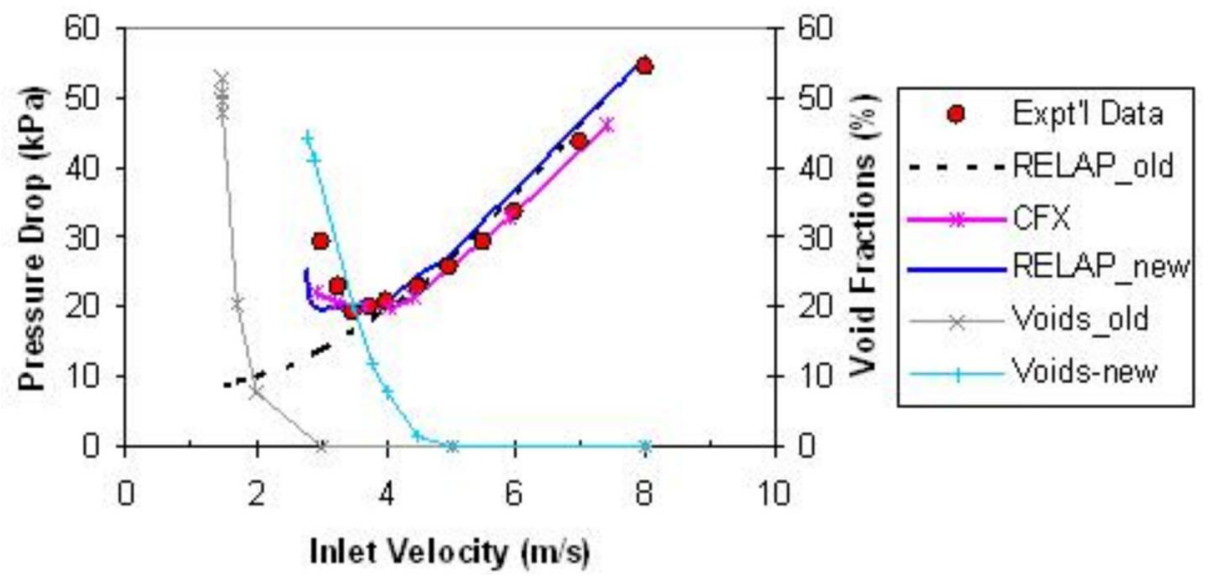

Figure 4: Pressure drop and void fraction profiles for an inlet temperature of $45^{\circ} \mathrm{C}$ and outlet pressure of $300 \mathrm{kPa}$ for a heat flux of $3 \mathrm{MW} / \mathrm{m}^{2}$. 


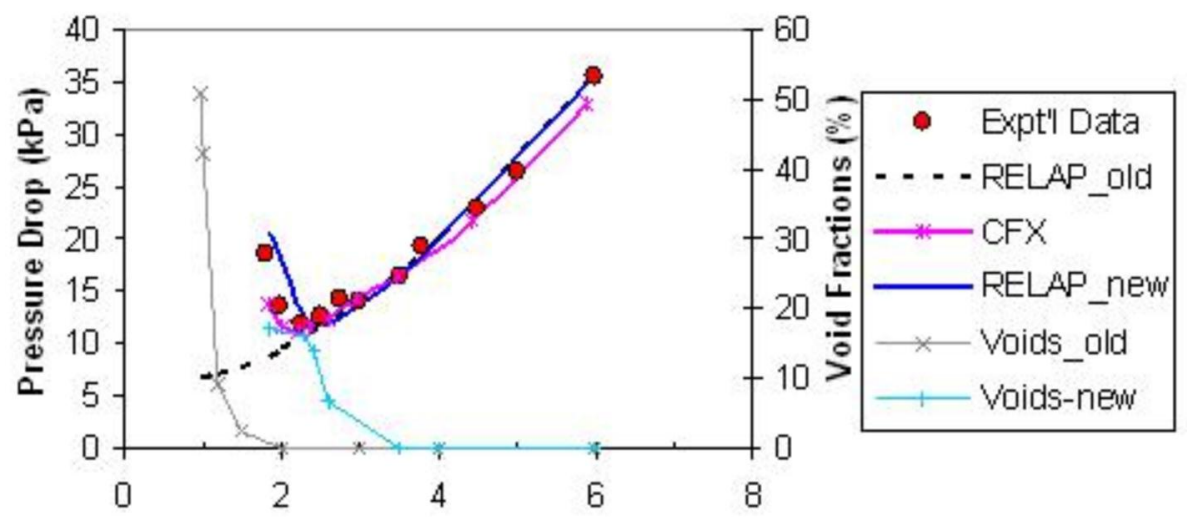

Inlet Velocity (m/s)

Figure 5: Pressure drop and void fraction profiles for an inlet temperature of $45^{\circ} \mathrm{C}$ and outlet pressure of $300 \mathrm{kPa}$ for a heat flux of $2 \mathrm{MW} / \mathrm{m}^{2}$.

fluxes of 4,3 and $2 \mathrm{MW} / \mathrm{m}^{2}$ respectively for an outlet pressure of $300 \mathrm{kPa}$ and $45^{\circ} \mathrm{C}$ inlet temperature. The occurrence of the flow instability is illustrated in experiments by the upward swing of the pressure drop plot when the critical inlet velocity is reached through steady reduction in the flow rate. Here, the RELAP5/MOD3.2 code (designated as RELAP-old) consistently under-predicts the occurrence of the onset of flow instability for all range of heat fluxes. However, the modified RELAP5/MOD3.2 code (designated as RELAP-new) provided a closer agreement with the experimental measurements, albeit with a slight under-prediction of the OFI with increasing heat flux. Note from Figure 3 that the upswing in the pressure drop curve was not well defined because the flow was inherently unstable. This observation is consistent with the findings of Li et al. [9] and Yeoh et al. [17].

The calculation of the OFI based on the predicted pressure drop-velocity curve can be carried-out by employing the void fraction criteria (that is, at OFI, the void fraction is about 10\%) as suggested by Yeoh et al. [17]. Since no void fraction measurements were taken in the original experiments, the 


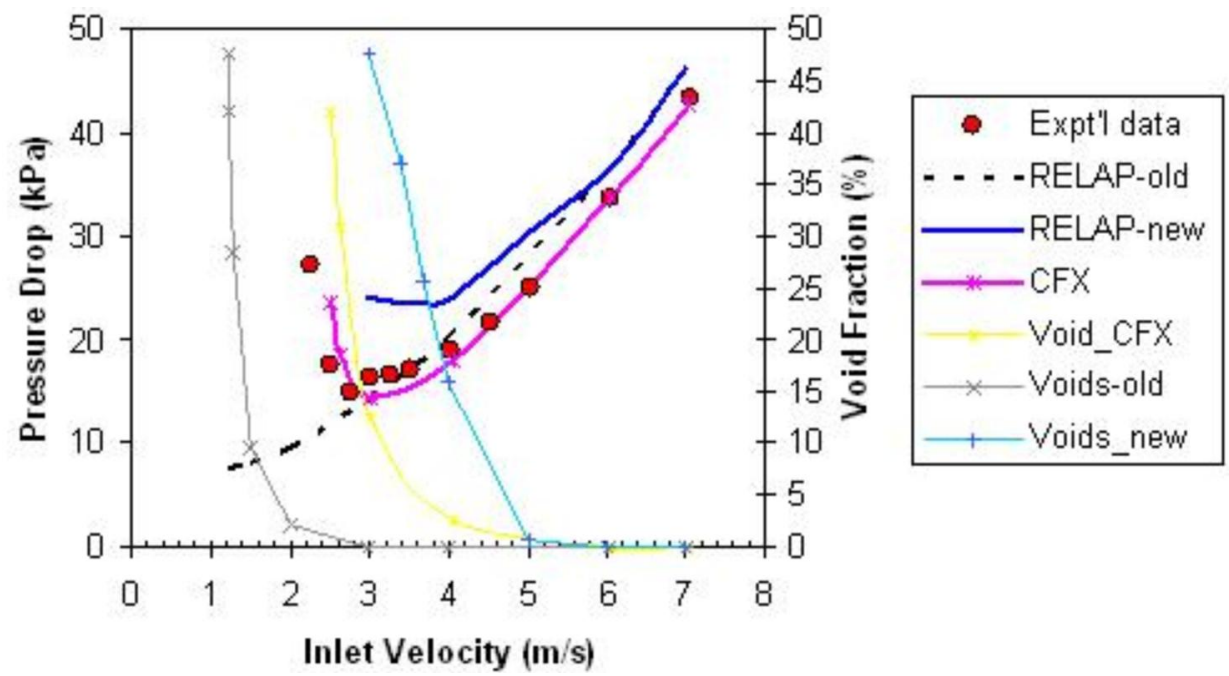

FigURE 6: Flow instability predictions at extreme subcooling conditions with outlet pressure of $300 \mathrm{kPa}$ and heat flux of $3 \mathrm{MW} / \mathrm{m}^{2}$ for an inlet temperature of $25^{\circ} \mathrm{C}$.

OFI for the experiment was estimated as the minima of the pressure drop inlet velocity curve.

The predictions obtained using CFX come closest to the experimental data as shown in Figures 3-7. This follows from earlier studies [9, 17] where improvements applied to the CFX code demonstrated void fraction profile predictions in close agreement with experimental data. This finding highlights the importance of the proper estimation of void fractions for improved characterization of subcooled boiling flows.

Figures 6 and 7 show CFX predictions conform well with experimental data in predicting the OFI in cases of extreme subcooling, whereas the modified RELAP code exhibited an apparent deficiency in this respect. RELAP-new gave a larger margin of over-prediction of the OFI for the higher subcooling case, although under-predicting the same for low subcooling conditions. This 


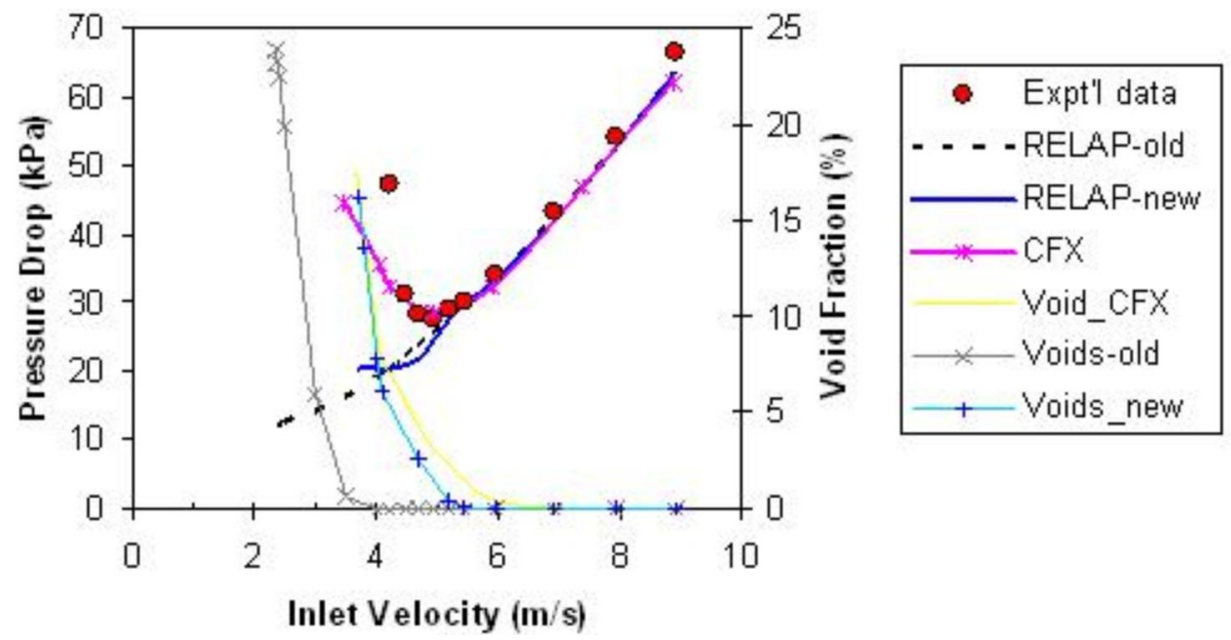

FigURE 7: Flow instability predictions at extreme subcooling conditions with outlet pressure of $300 \mathrm{kPa}$ and heat flux of $3 \mathrm{MW} / \mathrm{m}^{2}$ for inlet temperatures of (a) $25^{\circ} \mathrm{C}$ and (b) $65^{\circ} \mathrm{C}$.

was probably due to the specification of a constant bubble departure size at the heated wall. This greatly influenced the generation rate of the bubbles determined through the evaporation heat flux in the wall heat flux partition model.

The effect of varying heat flux on the calculated inlet velocity at OFI is illustrated in Figure 8. Results generated using RELAP-old were found to be consistently lower than the experimental values. This deficiency can be traced to the use of the Saha-Zuber correlation in the wall evaporation model. Tang [14] reported that the Saha-Zuber model yields a low estimate of the void fractions at the OFI. Calculated values from RELAP-new and CFX indicated a better agreement with experimental data. 


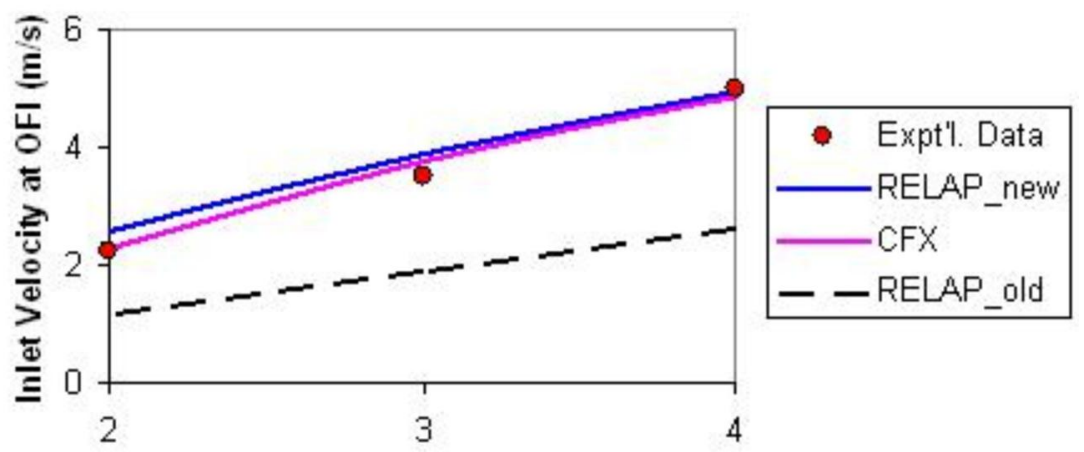

\section{Heat Flux $\left(\mathrm{MW} / \mathrm{m}^{2}\right)$}

FiguRE 8: Effect of heat flux on the onset of flow instability (OFI)

\section{Conclusion}

To enhance the capability of the nuclear safety code RELAP5/MOD3.2 to predict low-pressure subcooled boiling flow instabilities, an improved subcooled boiling model has been proposed. The proposed model features improved correlations for the mean bubble diameter and the implementation of the wall heat flux partition model with recent correlations that were employed in CFX4.4 used in earlier instability studies $[9,17]$. The modifications introduced in the RELAP5 code was validated against low-pressure subcooled boiling flow experiments and showed significant improvements in predicting the onset of the Ledinegg-type instability. In contrast, the default subcooled boiling model in the old RELAP code consistently under-predicted the occurrence of the onset of flow instability.

Predictions obtained using the enhanced CFX code agrees well with experimental data in all cases considered. Estimates of critical inlet velocities at OFI fall within $\pm 8 \%$ of experimental values.

The weakness manifested by the modified version of the RELAP 5 code in 
relation to the influence of subcooling is attributed to correlations used to predict the bubble departure diameter at the heated wall. Further investigations are underway to address this issue.

Acknowledgment: The authors are grateful for the financial support extended by ANSTO during the conduct of this study.

\section{References}

[1] AEA Technology, CFX 4.2: Solver, Didcot, Oxfordshire, UK, 1997. C1341

[2] R. W. Bowring, Physical model based on bubble detachment and calculation of steam voidage in the subcooled region of a heated channel, Report HPR-10, Institute for Atomenergi, Halden, Norway, 1962. C1340

[3] M. Courtaud, G. Coulon and F. Mazzili, Compte rendu d'essais boucle casimir traces de courbes ens, Centre D'etudes Nucleaires de Grenoble, Rapport TT/66-2-B/MC-GC/FM, 1966. C1343

[4] M. Courtaud and K. Schleisiek, Pertes de pression en ebullition locale a basse pression dans des canaux de section rectangulaire, Centre D'etudes Nucleaires de Grenoble, Rapport T.T. n 84, 1968. C1343

[5] C. D. Fletcher and R. R. Schultz, RELAP5/MOD3 code manual. User's Guidelines, NUREG/CR-5535, INEL-95/0174, Vol. 5, Rev. 1, 1995. C1341

[6] T. Hibiki and M. Ishii, Active nucleation site density in boiling systems, Int. J. Heat Mass Transfer, 46, 2587, 2003. C1338 
[7] R. L. Judd and K. S. Hwang, A comprehensive model for nucleate pool boiling heat transfer including microlayer evaporation, ASME J. Heat Transfer, 98, 623, 1976. C1340

[8] G. Kocamustafaogullari and M. Ishii, Foundation of the interfacial area transport equation and its closure relations, Int. J. Heat Mass Transfer, 38, 481, 1995. C1339, C1340

[9] Y. Li, G. H. Yeoh and J. Y. Tu, Numerical investigation of static flow instability in a low-pressure subcooled boiling channel, Heat Mass Transfer, 40, 355, 2004. C1337, C1338, C1339, C1346, C1347, C1349

[10] A. K. Nayak, P. K. Vijayan, V. Jain, D. Saha and R. K. Sinha, Study on the flow pattern-transition instability in a natural circulation heavy water moderated boiling light water cooled reactor, Nuc. Eng. Design, 225, 159, 2003. C1337, C1338

[11] V. Prodanovic, D. Fraser and M. Salcudean, On the transition from partial to fully developed subcooled flow boiling, Int. J. Heat Mass Transfer, 45, 4727, 2002. C1337, C1338

[12] J. T. Rogers and J.-H. Li, Prediction of the onset of significant void in flow boiling of water, ASME J. Heat Transfer, 116, 1049, 1994. C1340

[13] Q. Sun, R. Yang and H. Zhao, Predictive study of the incipient point of net vapor generation in low-flow subcooled boiling, Nuc. Eng. Design, 225, 249, 2003. C1337, C1338

[14] H. Tang, Study on void fraction distribution and flow instability in a natural circulation system with subcooled boiling, Ph.D. Thesis, Tsinghua University, Beijing, China, 1999. C1348

[15] J. Y. Tu and G. H. Yeoh, On numerical modeling of low-pressure subcooled boiling flows, Int. J. Heat Mass Transfer, 45, 1197, 2002. C1338, C1339 
[16] G. R. Warrier, N. Basu and V. K. Dhir, Interfacial heat transfer during subcooled flow boiling, Int. J. Heat Mass Transfer, 45, 3947, 2002. C1338

[17] G. H. Yeoh, J. Y. Tu and Y. Li, On void fraction distribution during two-phase boiling flow instability, Int. J. Heat Mass Transfer, 47, 413, 2004. C1337, C1338, C1339, C1341, C1346, C1347, C1349

[18] O. Zeitoun and M. Shoukri, Axial void fraction profile in low pressure subcooled flow boiling, Int. J. Heat Mass Transfer, 40, 867, 1997. C1339 